\title{
Research on the International Development Trend of Big Data and Digital Economy and Its Reference to China
}

\author{
ZHANG Tao' ${ }^{1}$, WU Zai-Qun ${ }^{2,}$, ZHENG Xiao-Yu ${ }^{3}$ \\ ${ }^{1}$ Information Engineering College, Baise University, Baise 533000, China \\ ${ }^{2}$ Information Engineering College, Baise University, Baise 533000, China \\ ${ }^{3}$ Chengdu Tianfu New District human intelligence light culture and art training school, Chengdu, 610000, China
}

\begin{abstract}
With the wide application and development of big data, digital economy has become the innovation power of global economic growth and has an important impact on the development of global social and economic cooperation. From an international perspective, this paper analyzes the development trend and achievements of the United States, the European Union and important international organizations in the field of digital economy. On this basis, this paper analyzes the current situation and challenges of the development of China's digital economy, and puts forward suggestions and measures to promote the development of China's digital economy in view of the digital gap, value assessment, development mode, talent training.
\end{abstract}

\section{INTRODUCTION}

In recent years, with the progress of big data, cloud computing, mobile Internet, Internet of things, artificial intelligence, block-chain and other technologies, data has gradually become an important resource for economic innovation and growth, job creation and social progress. Digital technology has been widely penetrated into all walks of life, which has greatly affected the economic operation and profoundly affected the government, enterprises and public Organization and personal life. It also gave birth to the new economic form of "digital economy". The concept of digital economy was first proposed by American scholar Tapscott d [1]. The concept of digital economy was further improved at the G20 Hangzhou summit in 2016. Digital economy refers to a series of economic activities that use digital knowledge and information as key production factors, modern information network as an important carrier, and effective use of information and communication technology as an important driving force for efficiency improvement and economic structure optimization [2].

At present, China's economy has shifted from the stage of high-speed growth to the stage of high-quality development. The new economic form of digital economy provides new impetus for high-quality development and plays an important role in accelerating economic development, improving the quality of economic development, promoting supply side structural reform, and promoting employment $[3,4]$. The Chinese government attaches great importance to the development of digital economy. Especially in October 2017, general secretary Xi Jinping proposed in nineteen major reports that we should speed up the construction of an innovative country, build "Digital China" and develop new industries such as digital economy. The digital economy in the future will become an important focus of implementing the new development concept and building a modern economic system. In addition, in the government work report in 2019, Premier Li Keqiang mentioned several contents related to digital economy, and proposed to deepen the research and application of big data and artificial intelligence and to cultivate new generation of information technology, highend equipment, bio-medicine, new energy vehicles, new materials and other emerging industrial clusters, so as to strengthen the digital economy.

\section{ANALYSIS ON THE DEVELOPMENT TREND OF DIGITAL ECONOMY IN FOREIGN COUNTRIES}

\subsection{Analysis on the development trend of digital economy in American}

Since the 1990s, the United States began to pay attention to the development of information infrastructure and digital technology, committed to the construction of digital economic ecosystem. In 2010, the United States put forward the concept of "digital nation" and released a number of "digital country" reports on infrastructure, Internet and mobile Internet. In 2015, the U.S. Department of Commerce issued the digital economy agenda, which regards the development of digital economy as the key to achieving national prosperity and maintaining competitiveness, and makes strategic arrangements in promoting data openness, information security, talent cultivation, and technological development. In 2018, the United States emphasized investment in the next generation infrastructure and promoting the development

"Corresponding author: 452442557@qq.com 
and use of advanced digital technology in policies such as the data science strategic plan and the U.S. national network strategy, so as to ensure that the United States maintains its technological advantages in emerging fields. In addition, in terms of theoretical research, the United States has formulated the connotation and measurement standards of digital economy, which will promote the understanding and measurement of digital economy in the new era. At the same time, the United States plays its first mover advantage in the field of digital economy, actively arranges Digital Trade and promotes its digital trade rules. The office of the U.S. Trade Representative (USTR) has established the digital trade working group (dtwg) to quickly identify digital trade barriers and formulate corresponding policy rules. With the support of the government, American enterprises have less regulatory problems in foreign markets, which is conducive to enterprises' participation in the global digital economy and opening up the global digital economy market.

\subsection{Analysis on the development trend of digital economy in Europe}

In the field of digital economy, the EU has issued a series of policies, such as the digital single market strategy, the general data protection regulations, the framework regulations on the free flow of non personal data within the EU, horizon Europe, etc., which ensure the free flow of non personal data within the EU, promote the establishment of a unified digital goods, services and capital market within the EU, and effectively promote the development of a unified digital goods, services and capital market Promote the development of digital economy in EU countries. The European Union also attaches great importance to the development of emerging fields of digital economy. In February 2020, the European Commission issued the white paper "European artificial intelligence development road for excellence and trust"[5], aiming to promote the development of artificial intelligence and deal with the risks brought about by the application of related technologies through strengthening investment and supervision.

Under the overall framework of the European Union, the United Kingdom has issued the "British digital strategy", "digital charter" and other documents, elaborating on how to build a world-class digital economy; France has issued a series of cutting-edge technology policies related to digital economy, such as "digital France 2020" and "plan for promoting industrial transformation with digital technology", to create a good environment for digitalization; Germany has issued a series of digital economy related cutting-edge technology policies Policies such as "digital strategy 2025", "high tech strategy 2025" and "national industrial strategy 2030" have been issued to promote the transformation of digital economy.

\subsection{Analysis on digital economy development of international organizations}

The United Nations will promote international cooperation in the field of digital economy as one of its priorities. Through the establishment of the high level group on digital cooperation and the world digital economic cooperation organization, the cooperation among governments, the private sector, civil society, international organizations, technical and academic circles and other relevant stakeholders in digital space has been effectively promoted. At the same time, through the coordination of international organizations, the United Nations enables different countries, communities and nations to use digital cooperation and technology to reach broad consensus, build an inclusive digital economy and society, and promote coordinated, balanced and sustainable development of countries and regions in the world.

G20 has keenly grasped the historic opportunities brought about by digitalization. Since the G20 digital economy development and Cooperation Initiative was adopted in Hangzhou in 2016, G20 members have been encouraged to carry out multi-level digital economic development exchanges, actively promote the strategic opening and cooperation of digital economy development, and build more strategic cooperation platforms. At present, G20 members are committed to promoting inclusive digitization, data flow and international e-commerce rules making, and are expected to achieve substantial results in 2020 .

The organization for economic cooperation and development (OECD) vigorously promotes countries to upgrade their digital economic policies into national strategies. In order to maximize the role of digital transformation and promote innovation, growth and social prosperity, OECD countries have set policy objectives in terms of the policy significance of digital transformation, improving the evaluation mechanism, and building an integrated policy framework. At present, more than 100 countries have agreed to reach an international consensus on how to tax multinational digital enterprises by 2020 .

\section{DEVELOPMENT STATUS AND CHALLENGES OF DIGITAL ECONOMY IN CHINA}

\subsection{The evolution of digital economy in China}

At the national level, the evolution of China's digital economy related policies has roughly experienced three stages.

In the early stage, the main characteristics of this stage are information construction and encouraging ecommerce. With the vigorous development of the Internet industry, information construction has entered a new stage.

In the promotion stage, mainly represented by the "Internet plus" blowout growth and the national strategy of big data. The State Council's guidance on promoting the "Internet plus" action was released in July 2015 as an important starting point. At the same time, the "national big data strategy" was put forward for the first time in the Fifth Plenary Session of the 18th CPC Central Committee in 2015, and the action outline for promoting the development of big data was issued, which marked that 
China has made an important plan in information resource sharing and government information disclosure.

In the growth stage, it is mainly represented by the deep integration of the real economy and the acceleration of the growth of emerging industries. In March 2017, Premier Li Keqiang mentioned the digital economy in the government work report, which further reflected the state's high attention to the digital economy. In 2019, the government work report clearly points out that it is necessary to accelerate the development of emerging industries. We will deepen the R \& D and application of big data and artificial intelligence, cultivate new generation of information technology, high-end equipment, biomedicine, new energy vehicles, new materials and other emerging industrial clusters, and expand the digital economy. We will adhere to inclusive and prudent supervision, support the development of new business forms and new models, and promote the healthy growth of platform economy and sharing economy. It shows that the development of digital economy has risen to the height of national strategy. In October 2019, during the sixth World Internet Conference, national development and Reform Committee and the central network and information office issued the implementation plan of the national digital economy innovation and development pilot zone, and awarded licenses to six "national digital economy innovation and development pilot zones" in Zhejiang, Hebei (xiong-an New Area), Fujian, Guangdong, Chongqing and Sichuan, officially starting the establishment work.

\subsection{Development of digital economy in major cities of China}

Since 2017, China has successively issued the national strategic outline and implementation plan of digital economy, and provinces have actively promoted the integrated development of digital economy, planning and guiding the development of local digital economy. Up to now, Guizhou, Guangdong, Anhui, Shandong, Zhejiang, Sichuan and other provinces and cities have issued relevant plans and Guidance Opinions on digital economy to support the development of digital economy from the perspectives of innovation and entrepreneurship, talent introduction and training, basic platform, application field, standards and specifications, finance and taxation, and industry investment fund. The "state province" secondary policy system has been initially established.

In terms of support for subdivision areas, local policies have diversified exploration and practice in terms of technology and scenarios. In the field of artificial intelligence, big data and virtual reality, Beijing, Shenzhen, Chengdu, Guiyang, Nanchang, Qingdao, Chongqing and other cities have formulated characteristic development policies to support industrial development and expand industrial advantages. Hangzhou, Guangzhou, Shanghai and other cities have actively tried and explored in the application fields of smart government, e-commerce, smart city and intelligent manufacturing, and are in the forefront of China. The policy exploration and practice in these sub areas have effectively promoted the diversified and characteristic development of digital economy in various regions.

\subsection{Challenges of digital economy development in China}

One is the "gap". The latest report on digital economy in 2019 issued by the United Nations mentioned that the new digital divide is forming. There are two main problems in China's digital divide: firstly, the gap between China and the major developed countries in the field of digital economy, especially in the field of new infrastructure and core technology, is still a problem that can not be ignored. Secondly, there is imbalance in the development of digital economy among provinces in China[6]. The development of digital economy in China's provinces is decreasing step by step from east to west. The regional differentiation is obvious and the development is unbalanced. The main reason is the reform of digital industry

The second is "value". The core value of digital economy is mainly reflected in two aspects: firstly, the value of data has become the key issue of digital economy. Data collection, storage and analysis of government, enterprises and other institutions, due to the phased development of informatization and digitization, as well as the large volume, various types and low value density of big data, the credibility and data association relationship of big data of government, enterprises and other institutions are extremely complex. In this context, how to determine the credibility of the data and the effectiveness of the resulting decision-making knowledge is a serious challenge. Secondly, the economic value and social value brought by digital economy lacks statistical and evaluation standards [7]. At present, how much economic value and social value has been produced by digital economy in China, whether it has a positive effect on improving productivity and whether it has really increased human welfare is a key point that needs to be paid attention to. It is urgent to carry out statistics and evaluation of digital economy. The statistical departments of the United States, Canada and other countries have estimated the scale of the digital economy based on the theory of national economic accounting. The China Institute of information and communications also uses the growth accounting framework to measure the scale of China's digital economy [7]. However, due to the different definitions and standards of digital economy, the results at home and abroad are not comparable. Therefore, it is an important challenge to establish a digital economic evaluation system that can be standardized and internationalized.

The third is "mode". As the digital economy is dependent on the essence of real economic development, the differences of regional economic structure may lead to differences in the direction and mode path of digital economy in each region, and each region is also striving to build a digital economy innovation platform. But are the digital technology driven mode, digital integration driven mode, digital resource driven mode, infrastructure driven mode or machine For the innovation driven mode, all localities need to determine the development mode of 
local digital economy based on their own foundation, resources, talents and technology. They should not be stereotyped and should be developed according to local conditions.

The fourth is "talent". The abilities of digital economy talents include digital leadership, digital operation ability and digital development potential. Personnel training of multi-level digital economy is an important factor affecting the sustainable development of China's digital economy. From the talent demand side, digital technologies such as big data, Internet of things and artificial intelligence iterate quickly. Compared with the rapid development of digital industry, the traditional talent training mode leads to the relatively fixed teaching contents and teaching methods of colleges and universities, which can not keep up with the rapid development of the industry. At present, the development of digital economy makes the organic connection between the supply side and the demand side of talents and between the education chain and the industrial chain more urgent, which is forcing the reform of talent training mode in digital economy.

\section{SUGGESTION ON THE DEVELOPMENT OF DIGITAL ECONOMY IN CHINA}

Based on the analysis of the development trend of digital economy at home and abroad, this paper puts forward some suggestions for the development of digital economy in China.

Firstly, we need to strengthen the top-level design of digital economy, coordinate new infrastructure construction and layout, and reduce the impact of "digital divide" on China's digital economy. We will give better play to the top-level design and guidance role of the government, improve the construction of information infrastructure, including network, storage, security, cloud computing, etc., and focus on accelerating the construction of new infrastructure, including $5 \mathrm{~g}$, artificial intelligence, Internet of things, industrial Internet, blockchain, etc.; data flow driven technology flow, talent flow, capital flow collection and sharing, effective distribution, will help to optimize the industrial structure, improve the overall industrial level and level, form a provincial and regional linkage development pattern, and promote the differentiated and coordinated development of various regions.

Secondly, we need to strengthen the use of digital resources, enhance the value of digital resources, and build digital economic statistics and evaluation system. First, integrate government, society and The third-party data resources can break through the "data island", promote the exchange and sharing of data resources, optimize the allocation of data resources, and manage the data resources, so that they become the core basic elements of the development of urban digital economy; the second is to promote the transformation of virtualized data resources into assets with real value through the commercialization of data resources, the liberalization of data circulation, the platform of data transaction and the regulation The third is to build a statistical system of digital economy and establish a statistical and evaluation index system that objectively reflects the overall development and dynamic operation of the digital economy. In order to evaluate the value of digital economy, we should consider the direct contribution, indirect contribution and welfare improvement of digital economy.

Thirdly, we will focus on digital empowerment, cultivate the soil of digital economy, and improve the level of comprehensive competition. On the one hand, we should comprehensively develop and strengthen the digital industry, focus on accelerating the development of intelligent terminal industry, big data industry and artificial intelligence industry, and actively explore and innovate $5 \mathrm{~g}$ scene application to develop new kinetic energy. On the other hand, we should actively promote the digital transformation and upgrading of the industry, deeply integrate the Internet, big data, artificial intelligence, Internet of things with the real economy, stimulate the new vitality of traditional industries, and promote the quality and efficiency improvement of traditional industries. We will deepen the application of digital technology and vigorously promote the cross industry, cross industry and cross regional integration, sharing and application practice of digital economy.

Lastly, we will explore the innovative mechanism of talent training and cultivate digital economy professionals at different levels. On the one hand, we should actively and deeply promote the integration of production and education in the field of digital economy, explore the construction of talent training system and mechanism of digital economy, and cultivate a group of knowledgebased, skilled and applied talents with high industry quality and strong application ability. On the other hand, guided by the development trend of local economy, industry development and the future needs of enterprises, we will launch in-depth school enterprise cooperation solutions to promote the innovation of digital talent cultivation in vocational colleges.

\section{SUMMARY}

As a new economic form, the development of digital economy has become a global consensus under the background of global informatization entering a new stage of comprehensive penetration, cross-border integration, accelerating innovation and leading development. Based on the analysis of the development trend and achievements of a series of digital economy in the United States, the European Union and important international organizations, and in view of the challenges existing in the development of China's digital economy, this paper puts forward a number of development suggestions and measures, so as to promote the healthy and sustainable development of China's digital economy.

\section{Authors}

Zhang Tao (1978-), from Baise University, doctor's degree, international MBA, professor. His main research interests are digital economy, digital government, big data, and the 
theory and application of social credit. Corresponding author: Wu Zaiqun* (1982 -), from Baise University, master's degree, associate professor. His main research interests are signal processing and control technology, artificial intelligence and big data. Zheng Xiaoyu (1984-), master's degree in international law.

\section{References}

1. Tapscott D. The digital economy: promise \& peril in the age of networked intelligence[M].NewYork: McGraw-Hill, 1995.

2. G20 summit in Hangzhou.G20 digital economy development and Cooperation Initiative

[EB/OL].

http://www.g20chn.org/hywj/dncgwj/201609/t20160 920_3474.html,2016.

3. Dingzhifan. Research on the mechanism of high quality economic development driven by digital economy: a theoretical analysis framework. Modern Economic Research[J],2020(01):85-92.

4. Gong xiaoying, Wang haifei. Research on the development and effect of contemporary digital economy.E-Government[J].2019(08):51-62.

5. European Commission high level expert group releases white paper. On Artificial Intelligence - A European Approach to Excellence and Trust[EB/OL].https://www.lexblog.com/2020/02/21/ europes-excellence-and-trust-in-ai/,2020.

6. Zhang xuening, Wu tiantian. Research on the spatial differentiation pattern of China's Provincial Digital Economy Development. The World of Survey and Research[J].2019(10):34-40.

7. China Institute of information and communications. China digital economy development and employment book[EB/OL].http://www.caict.ac.cn/kxyj/qwfb/bps/ 201904/t20190417_197904.htm,2019. 